\title{
O Grocianismo e a literatura de política externa brasileira na década de 1990.
}

Grocianism and the foreign policy literature in the 1990s.

\author{
André Francisco Matsuno da Frota ${ }^{1}$ \\ Rodrigo Miscchiatti Monteiro ${ }^{2}$
}

\section{RESUMO}

O objetivo deste artigo é reunir as interpretações sobre a política externa brasileira e o grocianismo, mediante uma revisão da literatura formada pelos autores, Lafer (2009), Cervo (2002), Pinheiro (2000), Fonseca Jr. (1998), Vigevani, Oliveira e Cintra (2003) e Lessa Couto e Faria (2010), que analisam o significado e o entendimento dessa associação. A exposição sintetiza o argumento dos autores, seguida por considerações da interface entre o grocianismo e a política externa, e encerra com uma sugestão de organização do debate, entre interpretações realistas, idealistas, $e$ racionalistas sobre o significado do grocianismo.

Palavras-chave: Grocianismo; política externa brasileira; Racionalismo

\begin{abstract}
The objective of this article is to reunite the interpretations about the Brazilian foreign policy and Grotianism, by a literature review by the authors, Lafer (2009), Cervo (2002), Pinheiro (2000), Fonseca Jr. (1998), Vigevani, Oliveira e Cintra (2003) e Lessa Couto e Faria (2010), who analyze the meaning and the understanding of that association. The exposition synthetizes the author's arguments, followed by consideration of the interface between Grotianism and the foreign policy, and it ends with a suggestion of organization about the debate between realists, idealists and rationalists about the meaning of Grotianism.
\end{abstract}

Key-words: Grotianism; Brazilian foreign policy; Racionalism

\section{INTRODUÇÃO}

\footnotetext{
${ }^{1}$ Mestre em Ciência Política (UFPR), Especialista em Análise Ambiental (UFPR), Graduado em Geografia (UFPR). Professor do Grupo Educacional UNINTER. Curitiba, Brasil.

${ }^{2}$ Graduando em Relações Internacionais (UNINTER); Graduando em Letras (UTFPR). Curitiba, Brasil.

Conjuntura Global, vol. 5 n. 1, jan./abr., 2016, p. 94-114. 
A exposição desenvolvida a seguir tem por objetivo estabelecer um diálogo entre a literatura de política externa e a escola inglesa de relações internacionais, mediante o conceito de grocianismo/racionalismo ${ }^{3}$. Deste modo, inicia a exposição, com uma breve apresentação da influência do grocianismo em atores da política exterior brasileira, como o ministro Celso Lafer e o embaixador Gelson Fonseca Jr. Em seguida, uma revisão de literatura dos autores da política externa na década de 1990 é apresentada, com o objetivo de demonstrar a maneira, como os analistas de relações internacionais, interpretaram o significado e a influência do grocianismo na inserção multilateral do Brasil. Por fim, conclui-se com uma sugestão de classificação da literatura em interpretações realistas, racionalistas e revolucionistas da inserção multilateral do Brasil.

A revisão supracitada inicia com o paradigma sugerido por Fonseca Jr. (1998) e complementada por Tullo Vigevani, Marcelo de Oliveira e Rodrigo Cintra (2003), em que os autores demonstram uma mudança de ênfase da política externa brasileira, a priori de "autonomia pela distância" no período da Guerra Fria e, em seguida, de "autonomia pela participação" e de "autonomia pela integração". A segunda representa uma ressalva à tese do distanciamento do Brasil ao multilateralismo, sugerida por Lessa, Couto e Farias (2010). A terceira interpretação é sugerida por Letícia Pinheiro, mediante o conceito de "institucionalismo pragmático" e do "paradoxo" entre discurso e ação diplomática do país nos anos 1990. A quarta interpretação é dada por Amado Luis Cervo (2002), uma abordagem crítica da atuação do Brasil, em que o autor intitula de "dança de paradigmas". As quatro proposições teóricas, como será demonstrado, auxiliam a demonstrar a relação entre o grocianismo e a política externa brasileira.

3 O racionalismo é uma denominação criada por Martin Wight (1987). O uso do termo, tal como Martin Wight estabeleceu, refere-se a uma perspectiva que rompe com a divisão clássica entre realismo e idealismo, identificando um caminho intermediário entre as duas tradições. Neste sentido, racionalismo é um sinônimo para o termo grocianismo. Racionalismo ou grocianismo, significa uma possibilidade intermediária entre uma interpretação hobbesiana, ou realista e outra kantiana ou revolucionista. O artigo "international theory: three traditions" publicado por Wight em 1987 inaugura a terminologia. No entanto, o termo racionalismo, também foi utilizado no final dos anos $1980 \mathrm{em}$ um artigo lançado por Keohane (1988 apud NOGUEIRA; MESSARI, 2005), em que o autor adverte para um debate entre racionalistas e reflexivistas. $\mathrm{O}$ uso do termo racionalistas, realizada por Keohane (1988) é distinto do entendimento de Wight (1987) do termo. Para Keohane (1988) o racionalismo implica uma interpretação no qual os indivíduos buscam maximizar os seus ganhos e minimizar suas perdas. Por outro lado, Wight (1987) entende o racionalismo como um comportamento de síntese, uma visão dialética, uma tentativa de se livrar de posições caraterizadas pelos extremos do realismo e do idealismo.

Conjuntura Global, vol. 5 n. 1, jan./abr., 2016, p. 94-114. 


\section{O Grocianismo e a política externa brasileira}

A literatura grociana de política externa no Brasil possui, em Lafer (2009) e Fonseca Jr. (1998), dois escritores e, especialmente, atores estrategistas dos governos Itamar Franco e Fernando Henrique Cardoso. Souza (2015), ao discorrer a respeito do impulso dado aos estudos de Relações Internacionais nas academias latino-americanas na segunda metade do século XX, traça um paralelo entre o Grocianismo e a política externa brasileira, em especial a influência da Escola Inglesa ${ }^{4}$ em autores como Lafer e Fonseca Jr. Nas décadas de 1970 e 1980, para o autor, as análises de política externa no Brasil foram orientadas para uma inserção do país em uma ordem mundial de feição multipolar, na qual instituições internacionais e a busca por "consensos" dariam espaço de atuação mais autônoma e assertiva para potências intermediárias como o Brasil. 0 autor menciona a relevância da perspectiva grociana para analisar os paradigmas da "autonomia pela distância" e "autonomia pela participação"5, os quais caracterizaram a política exterior do Brasil, respectivamente, na Guerra Fria e nos anos 1990 (SOUZA, 2015, p. 43-44).

Souza (2015) ainda menciona que esses "traços grocianos" estiveram presentes no discurso da diplomacia brasileira na década de 1990, além de acompanharem a tentativa de inserção do Brasil enquanto potência intermediária e geradora de consensos na nova ordem global, marcada pelo fim da bipolaridade e pela intensificação do globalismo. 0 autor expõe que, tal como ocorrido na década anterior, quando havia a visão de que o período "passava por uma disjunção entre ordem e poder" (SOUZA, 2015, p. 41), autores como Lafer e Fonseca Jr. buscaram encontrar o espaço do país na nova conjuntura internacional dos anos 1990. "Assim, como nos anos 1980, buscam o lugar das potências

\footnotetext{
${ }^{4}$ A Escola Inglesa, reunindo autores como Adam Watson, Hedley Bull e outros acadêmicos, tem raízes na tradição racionalista ou grociana de RI, em especial as contribuições teóricas de Martin Wight e a herança do pensamento do jurista holandês Hugo Grócio. Além de explorar a questão da ordem internacional e das disputas de poder entre os Estados, a Escola Inglesa desenvolve o conceito de "sociedade internacional", entendida como resultado do aprofundamento da interação entre os Estados no Sistema Internacional, os quais teriam um conjunto de regras, interesses e valores compartilhados (SOUZA, 2015, p. 37). A ideia de "sociedade internacional", conforme Souza (2015, p. 37), "demonstra as preocupações normativas dos membros da Escola Inglesa com as regras, normas, leis e princípios de legitimidade que sustentam a ordem mundial".

${ }^{5} \mathrm{O}$ conceito de "autonomia" representa tema central da política externa brasileira, sendo utilizado pela literatura de política externa como referência para definir o grau de independência das decisões tomadas pelo Brasil em sua inserção internacional. Ao longo da história contemporânea da política exterior brasileira, o país teve fases autônomas em relação aos EUA e outras fases americanistas. Em geral, a dicotomia autonomia/dependência é identificada em relação ao perfil de relação bilateral com os EUA. Pode-se afirmar a existência de um debate latino-americano a respeito do binômio autonomia/dependência, tanto no âmbito econômico, quanto no âmbito político. Para informação, ver Moura (1982); Hurrell (1986); Tickner (2003 e 2008); Vigevani e Cepaluni (2009). Conjuntura Global, vol. 5 n. 1, jan./abr., 2016, p. 94-114. 
intermediárias para influenciar os processos decisórios internacionais" (SOUZA, 2015, p. 43).

Neste sentido, a década de 1980 representou, para um núcleo de diplomatas brasileiros, o esforço de incorporação da publicação do livro de Hedley Bull: $A$ sociedade anárquica, em 1977. Em especial, conforme entrevista realizada por Souza (2015), o diplomata, lotado na embaixada brasileira em Londres, José Guilherme Merquior, inclui na sua tese apresentada ao Curso de Altos Estudos (CAE) do Instituto Rio Branco (IRBR) as observações realizadas por Hedley Bull. No entanto, Merquior deteve um papel de ligação entre Bull e a diplomacia brasileira, também por apresentar à escola inglesa ao futuro chanceler Celso Lafer.

\begin{abstract}
Foi muito pertinente a sugestão de José Guilherme [Merquior], pois um dos méritos da proposta analítica de Bull é a da existência de uma sociedade internacional que vá além do sistema interestatal, pois este sistema interestatal vai criando, por mútuo acordo, normas e instituições para a conduta de suas relações e reconhecem um interesse comum na manutenção destes arranjos para a vida internacional. É a existência destas normas e instituições, destes arranjos, que configuram uma sociedade internacional. Esta enriquece o conceito do sistema, permitindo que a análise das relações internacionais não se veja limitada apenas à discussão das relações de poder entre os estados, incorporando ao mesmo tempo a historicidade e o seu impacto na configuração do sistema internacional. Foi este horizonte reflexivo que me ajudou no aprofundamento do tema da ordem mundial no ensaio que integra Paradoxos $e$ Possibilidades (Entrevista com Lafer, 2013). (SOUZA, 2015, p. 41).
\end{abstract}

Souza (2015, p.41) procura demonstrar que o livro "Paradoxos e Possibilidades: Estudos sobre a ordem mundial e sobre a política exterior do Brasil num sistema internacional em transformação, de 1982, é possivelmente a primeira publicação no Brasil e talvez na América Latina a incorporar de maneira sistemática e consistente os trabalhos de Bull e também de Martin Wight”. Em linhas gerais, Lafer e Fonseca Jr. irão representar a influência da escola inglesa de relações internacionais no pensamento e no discurso diplomático brasileiro, desde a publicação do livro de Hedley Bull até as sucessivas publicações de ambos os autores, ao adaptarem as premissas de Bull sobre os fundamentos da ordem e, consequentemente, da existência de uma sociedade internacional.

Como consequência da influência da matriz ideacional da escola inglesa, no pensamento diplomático brasileiro, cria-se um debate entre acadêmicos de relações internacionais, como Cervo (2012) e Pinheiro (2000) ao interpretarem o significado desta 
influência ideacional e, também, teorética na execução da política exterior brasileira na década de 1990. Em especial a literatura de política exterior apresentará, por um lado, argumentos descritivos e analíticos, como é o caso de Fonseca Jr. (1998), T. Vigevani, M. Oliveira e R. Cintra (2003), mediante fases de maior de menor engajamento com a sociedade internacional, por eles representada simbolicamente pela inserção multilateral. De outro lado, Cervo (2012) e Pinheiro (2000) escreverão criticamente a respeito deste perfil de inserção e de discurso diplomático grociano, procurando demonstrar a existência de uma "ilusão kantiana/grociana", como afirma Cervo (2012), ou mesmo demonstrar a vinculação desta relação, apenas como um discurso diplomático, conforme afirma Pinheiro (2000).

A sequência da exposição aqui sugerida procura revisar os tipos de entendimento da incorporação do grocianismo na política externa brasileira. Os autores citados em sequência visualizaram essa relação pelo tipo e característica de inserção multilateral. Nota-se uma aproximação entre sociedade internacional e engajamento multilateral, como forma de compreensão da existência de uma ordem internacional, regida não apenas por objetivos, mas também por valores.

\section{Os pares da "autonomia pela distância", pela "participação" e pela “integração"}

A análise da política externa na década de 1990 foi descrita por Fonseca Jr. e aprofundada por Vigevani, Oliveira e Cintra como um período em que o Brasil busca uma "autonomia pela participação" e, em seguida, uma "autonomia pela integração". Ao sugerir o conceito, os autores têm por objetivo demonstrar uma mudança na orientação da conduta externa voltada, a partir de então, para um incremento na participação aos mecanismos e às regras da sociedade internacional. A hipótese central dos autores destaca a substituição de uma agenda reativa, explicitada pela racionalidade da “autonomia pela distância", por uma agenda proativa, baseada na racionalidade da "autonomia pela participação e pela integração" ${ }^{6}$.

6 As duas modalidades de autonomia, seja pela distância ou pela participação/integração, representam entendimentos distintos da relação entre interesses nacionais e valores nacionais. Ocorre, a partir do fim da Guerra Fria e, também, do final da Ditadura Militar no Brasil, uma inclinação da política externa para participar dos mecanismos de regulação das relações entre os Estados. O distanciamento das regras do jogo seria uma aposta descontextualizada e anacrônica, diante da sociedade internacional do Pós-guerra. Neste cenário, o exercício da autonomia passa necessariamente pelos embates no interior da arquitetura jurídica internacional. 
Segundo Vigevani, Oliveira e Cintra (2003), o desenvolvimento nacional, interesse permanente do País, passa a estar diretamente relacionado com uma maior participação nos mecanismos da governança global. A opção pela inclusão do Brasil aos acordos, às normas e aos novos temas da agenda, como meio ambiente, direitos humanos, narcotráfico, concedem maior credibilidade ao País e, portanto, aumentam a margem de interferência na definição das regras do jogo. A noção de Global Player, um ator com interesses de amplo alcance, passa a relacionar-se a um engajamento construtivo diante das normas e das regras da sociedade internacional.

Vigevani, Oliveira e Cintra (2003) afirmam que a busca pela participação, especialmente durante o governo FHC, foi uma constante. Passa a ocorrer uma mudança no perfil de atuação, estabelecido por Araújo Castro em 1963, de resistência ao congelamento de poder derivado dos acordos conduzidos pelos países desenvolvidos. 0 conhecido discurso dos três D's - notadamente desenvolvimento, descolonização e desarmamento - proferido na Assembleia Geral das Nações Unidas (AGNU), evidenciou o perfil crítico da política externa diante da possibilidade de congelamento e, portanto, manutenção da hierarquia do poder na sociedade de Estados.

No entender de Vigevani, Oliveira e Cintra (2003), citando Castro, a polarização ideológica da Guerra Fria conduzia os estados a aumentarem seus gastos militares em detrimento da demanda mundial voltada para o desenvolvimento. A ligação entre guerra e subdesenvolvimento impedia a formação de um ciclo virtuoso de desenvolvimento e desarmamento. De fato, esta era a recomendação de Castro ao efetuar o discurso dos três D’s, em que os países desenvolvidos deviam reverter a lógica citada, reorientando os gastos militares para auxiliar as economias menos desenvolvidas.

O distanciamento do Brasil em participar do jogo polarizado da Guerra Fria refletiase na estratégia da "autonomia pela distância". 0 espaço de manobra independente visado necessitava de distanciamento dos embates ideológicos. Com a mudança do sistema internacional, após a queda do regime soviético, uma maior convergência de interesses passou a vigorar. 0 eixo Oeste-Leste foi flexibilizado, possibilitando um maior adensamento da sociedade internacional. Ampliou-se a percepção de interesses e de valores comuns, de modo a desobstruir os mecanismos de governança global.

A inflexão para uma conduta de participação, apontada por Fonseca Jr. e por Vigevani, Oliveira e Cintra, evidencia uma adaptação da política externa ao movimento da Conjuntura Global, vol. 5 n. 1, jan./abr., 2016, p. 94-114. 
sociedade internacional. 0 novo formato desta, com o Pós-guerra Fria, aumentou o grau de convergência entre os objetivos da política externa brasileira e as possibilidades abertas pelo contexto internacional.

As três interpretações do conceito de autonomia, "distância-participaçãointegração", categoria-chave da literatura de política externa, revelam uma mudança de concepção na forma de se relacionar com o movimento da sociedade internacional. Ao analisarmos a interação entre estas duas dimensões, nota-se o que Fonseca Jr. intitula de continuum nas relações internacionais. 0 conceito evidencia uma mobilidade histórica dos agentes e, em especial, das relações estabelecidas entre eles em direção à maior interação, com as regras da sociedade internacional.

\section{0 desejo de participação da sociedade internacional como uma constante}

Lessa, Couto e Farias (2010) iniciam o argumento com o objetivo de examinar a atuação multilateral brasileira durante a Guerra Fria, mediante o confronto com dados de votações na Assembleia Geral e com memorandos e telegramas das embaixadas brasileiras. Eles procuram confrontar a tese de distanciamento do Itamaraty em relação ao âmbito multilateral, introduzido por Fonseca Jr. e reforçado por Pinheiro (2000), Lima (2003), Villa (2006), Vigevani, Oliveira e Cintra (2003), Vigevani e Oliveira (2007).

A análise de Lessa, Couto e Farias (2010) procura flexibilizar a dicotomia, amplamente aceita pelo campo, de que é possível identificar distanciamento/participação entre o fim da Segunda Guerra Mundial e o fim da Guerra Fria, respectivamente. A tese de Lessa é a de que a ação multilateral brasileira não pode ser generalizada mediante o conceito de distância. 0 estudo de dois casos-chave, meio ambiente e comércio internacional, revela que tal ação "[...] longe de manter sistemática distância, ausência, isolacionismo ou não participação; [...], muitas vezes ela não derivava de uma opção tática da diplomacia do país". (LESSA; COUTO; FARIAS, 2010, p. 335).

\footnotetext{
7 Entre os objetivos permanentes do País destaca-se a busca pelo desenvolvimento, entendida no Pós-guerra como dependente da participação na elaboração das regras a serem definidas pelos países membros da sociedade internacional. De fato, a década de 1990 é considerada a década das conferências de alcance mundial. Logo, a estratégia de desenvolvimento passaria pela possibilidade de influenciar as decisões celebradas em consonância com os demais Estados.
} 
A antítese apresentada por Lessa, Couto e Farias (2010), incide diretamente no diálogo estabelecido com a literatura, uma vez que rompe a dicotomia distanciamento/participação, e, portanto, permite identificar o Grocianismo como uma característica de maior permanência da política externa, tal como defendido por Lafer. Em segundo lugar, a antítese contra-argumenta uma das premissas de Letícia Pinheiro, na qual o Brasil teria o realismo, como característica de maior permanência, ao ser comparado ao Grocianismo.

A problematização introduzida por Lessa, Couto e Farias (2010), procura questionar três aspectos da dicotomia distância/participação: a) considerar a distância, como um conceito correspondente à defesa ou contração no comportamento da diplomacia brasileira; b) entender que a falta de participação pode ser considerada uma característica intencional da distância; c) ver que o distanciamento do Brasil deriva, em certa medida, da divergência do País com os debates multilaterais da Guerra Fria. Os três aspectos representam facetas do problema formulado anteriormente.

O início da argumentação de Lessa, Couto e Farias (2010), vai estabelecer uma distinção entre intenção e ação diplomática. A análise busca demonstrar a existência de uma intenção de participação durante a Guerra Fria, limitada por razões de natureza orçamentária e administrativa da União. Ainda que existisse um "ceticismo" do governo em relação aos resultados das negociações multilaterais, essa postura não podia ser generalizada.

O aspecto central da proposição dos autores está no fato de o engajamento multilateral ter um custo. A participação implicaria em um custo a ser pago, almejável pelo Ministério das Relações Exteriores (MRE), porém limitado pelas restrições orçamentárias do órgão. Os autores apontam um "interesse acadêmico" pelo envolvimento nas reuniões, distanciados das "resoluções de interesse prático". Deste modo, o engajamento deveria pautar-se por três diretrizes: a) a participação apenas em reuniões em que houvesse interesses diretos do país; b) a representação do Brasil deveria ser realizada por um funcionário do MRE; c) a presença de técnicos das demais áreas deveria ser limitada ao estritamente necessário (LESSA; COUTO; FARIAS, 2010, p. 339).

A influência das restrições orçamentárias representou uma variável desconsiderada pelo paradigma desenvolvido por Fonseca Jr. (1998). Até o período posterior à Guerra Fria, o Brasil abdicou da participação em exercícios conjuntos devido a questões Conjuntura Global, vol. 5 n. 1, jan./abr., 2016, p. 94-114. 
financeiras. Os autores citam trechos da Rodada Uruguay do Acordo Geral sobre Tarifas e Comércio - General Agreement on Tariffs and Trade - (GATT), em que múltiplas reuniões ocorriam de maneira simultânea e faltavam recursos humanos para acompanhar todos os $\operatorname{acordos}^{8}$.

A análise da documentação usada por Lessa, Couto e Farias (2010) permite concluir que não há uma estratégia intencional de distanciamento derivada dos formuladores da política externa. Nesse sentido, ainda que os resultados colhidos pelo País demonstrem uma ausência de participação, os pressupostos ideacionais encontrados impedem a utilização generalizada dos extremos distância/participação, como categorias com limites definidos. 0 fato pode ser notado mesmo durante o período considerado participativo pela literatura de política externa, e isso significa identificar uma intenção de maior alcance, ou permanência na história diplomática, orientada pela busca/desejo de participação.

\section{Discurso grociano e práxis realista}

Uma segunda interpretação possível para o tipo de engajamento multilateral estabelecido pelo Brasil, durante a década de 1990, é fornecida por Letícia Pinheiro. A autora denomina o período no qual ocorre essa orientação de "institucionalismo pragmático", um conceito criado com a finalidade de reinterpretar o discurso grociano da política externa, mediante os traços de permanência na inserção multilateral do Brasil.

A elaboração baseia-se na constante busca pela autonomia, como a variável de maior centralidade na política externa brasileira. Mediante a relação entre o grau de autonomia e o grau de institucionalização, Pinheiro reinterpreta o grocianismo como uma modalidade do realismo. Em seu entendimento, o traço de maior permanência é identificado com um realismo situado entre duas variações extremas: o hobbesiano e o grociano. A autora identifica esta posição realista intermediária, como uma postura voltada para preservar a autonomia, diante do grau de integração com os regimes internacionais. 0 conceito de "institucionalismo pragmático" contém esse pressuposto

8 As correspondências entre o MRE e a delegação brasileira em Genebra evidenciam pedidos de maior número de técnicos para acompanhar e, por óbvio, aumentar a capacidade de influência na redação dos acordos. Rubens Ricúpero, embaixador da Missão do Brasil em Genebra entre 1987 e 1991, demonstrava preocupação diante da ausência de participação do Brasil em tabuleiros de negociação estratégica para os interesses nacionais. 
teórico, no qual o envolvimento multilateral é conduzido pela busca permanente de autonomia externa.

O artigo, no qual a autora desenvolve a discussão, inicia com uma digressão a respeito da interface entre a prática da política externa e as teorias de relações internacionais; em seguida, Pinheiro procura avaliar os fundamentos teóricos que sustentam o constante "desejo de autonomia", tal como descrito por Fonseca Jr.; e, por fim, apresenta a hipótese na qual a reorientação assumida pela política externa na década de 1990 está inserida em uma posição intermediária entre um realismo de natureza hobbesiana e um realismo de natureza grociana. A denominação para esta posição ocupada pelo Brasil foi intitulada de "institucionalismo pragmático", como mencionado.

A primeira seção da argumentação criada retoma uma divisão generalizada em três fases contrastantes da política externa: a) do começo do século XX até a década de 1950, marcado pelas vicissitudes da noção de "equidistância pragmática" (MOURA, 1980 apud PINHEIRO, 2000); b) o período da política externa independente, de 1961 até 1964, na qual surge uma diversificação de parcerias; c) interrompida entre 1964 e 1974, quando uma orientação norte-americana se estabelece. Dada a amplitude cronológica da classificação, Pinheiro resume em duas tendências históricas conflitantes da inserção internacional: o americanismo e o globalismo.

A primeira, inaugurada pelas opções do Barão do Rio Branco, deslocou o legado colonial de enquadramento dependente Brasil-Europa, para uma aliança tácita e ativa, com a potência emergente do começo do século XX: os EUA. A lógica da política externa do Barão visualizava a possibilidade de maiores ganhos relativos do País mediante a aliança com os EUA. O tema da autonomia, nesse contexto, estava depositado nas possibilidades advindas de um distanciamento das relações com o antigo continente para o novo mundo. A relação entre interesses e valores inaugurada combinou o pragmatismo, o americanismo e, em particular, o pacifismo. A fórmula de engajamento criada reuniu estes três componentes como método de atuação da diplomacia nacional. Os fins eram a demarcação de fronteiras e o aumento da autonomia extra-hemisférica. Ora, o americanismo, legado do patrono da diplomacia brasileira, entendia a relação com os EUA como um ganho de autonomia para o País.

O segundo conceito citado por Pinheiro - o globalismo - é desenvolvido mediante um esgotamento das relações estratégicas do País com os EUA. 0 governo Dutra, em 1945, Conjuntura Global, vol. 5 n. 1, jan./abr., 2016, p. 94-114. 
representou o início deste declínio na modalidade de relação bilateral herdada. Após o fim da Segunda Guerra Mundial, a América do Sul foi considerada como uma região de influência consolidada pelos norte-americanos. Os retornos e a barganha entre o Brasil e os EUA, de grande intensidade até a metade do século XX, foram substituídos por uma relação com poucos dividendos para ambos. 0 esgotamento desse modelo forçou a política externa a diversificar suas relações, tanto no eixo vertical como no horizontal. 0 globalismo, uma adaptação na lógica de atuação externa, substituiu o americanismo como estratégia de engajamento. A autonomia nacional, a partir de então, passou a ser entendida como dependente da multiplicidade de parcerias estabelecidas.

Os dois conceitos trazidos pela autora simplificam a história da política externa nas duas tendências, conforme explicitado. A esta distinção, porém, Pinheiro acrescenta nuances relevantes para a interpretação das ações do Brasil no período. A sugestão dela inclui a seguinte subdivisão: americanismo pragmático, 1902-1945, 1951-1961 e 19671974; americanismo ideológico, 1946-1951 e 1964-1967; globalismo grociano 1961-65; e, enfim, globalismo hobbesiano, 1974-1990.

As distintas fases e modalidades trazidas por Pinheiro revelam, de acordo com a autora, uma característica constante na política externa: a busca pela autonomia. A conclusão da digressão histórica sinaliza para uma adaptação das opções assumidas pelo Brasil, diante de seu constante desejo de autonomia. 0 seguinte problema interpretativo enfrentado por Pinheiro diz respeito a como compreender os anos 1990, no qual os estrategistas do período afirmam dotar a política externa de uma orientação grociana de inserção. Segundo Pinheiro, o discurso desses atores necessita de adequada contextualização com os traços permanentes do Brasil na história, ou seja, a busca pela autonomia e o realismo.

De modo a oferecer uma resposta interpretativa ao paradoxo dos anos 1990, a autora flexibiliza o entendimento do realismo em duas modalidades: um realismo hobbesiano e um realismo grociano. 0 objetivo é demonstrar uma flexibilidade de atuação e, portanto, de compreensão dos paradigmas em um mesmo período histórico. Para Pinheiro, a década de 1990 introduz o questionamento para o analista, o qual se depara, por um lado, com um traço de permanência na política externa ao analisar a história e, por outro lado, com o discurso dos estrategistas defendendo um estilo grociano de atuação. 
O raciocínio complementar fornecido como resposta ao aparente paradoxo é aprofundado ao serem conjugadas duas variáveis chave para a hipótese supracitada. Por um lado, o desejo de autonomia e, por outro, o grau de institucionalização ao qual a diplomacia aceita estar submetida. 0 tipo de relação entre ambas as variáveis evidencia duas modalidades de relação com as instituições internacionais. Uma primeira, mantida na América do Sul, demonstra um baixo nível de institucionalidade, enquanto a segunda, nas instituições multilaterais globais como as Nações Unidas, revelam alto grau de institucionalização aceita pelo País. Os dois tipos de relação, mantidas de maneira proposital, resolvem o aparente paradoxo do grocianismo na década de 1990. Na América do Sul, onde o País detém posição de liderança e, portanto, pode influenciar os organismos regionais em direção a um maior ou menor grau de institucionalização, a opção, então, é pelo menor nível.

De fato, os interesses relativos do País no entorno regional são mais visíveis do que no âmbito extra-hemisférico. Neste sentido, o espaço de autonomia intraorganizacional é mantido em nível elevado. Ao contrário, para além do continente sul-americano, admite-se maior grau de institucionalização e, logo, de menor autonomia.

Em síntese, o entendimento de Pinheiro (2000) demonstra que a leitura grociana da política externa brasileira nos anos 1990, contém uma duplicidade na forma de entender o conceito, bem como um critério de distinção geográfico. A adaptação do conceito aos traços de permanência histórica, notadamente vinculados ao realismo, fez com que o grocianismo detivesse uma orientação pragmática e pluralista, em termos ontológicos. A autora, portanto, ressignifica o entendimento do grocianismo à luz da história diplomática nacional.

\section{A ilusão grociana}

O terceiro dos estudos da trilogia selecionada contém o conceito de "dança de paradigmas", elaborado por Cervo (2002), para analisar os anos 1990, em geral, e o governo Cardoso, em particular. A análise desenvolvida situa o grocianismo como uma modalidade de idealismo, exatamente o oposto da argumentação de Pinheiro, a qual situa o grocianismo como uma modalidade de realismo. 
A abordagem, de cunho histórico, aplicada pelos autores procura demonstrar a reorientação da política externa brasileira após a redemocratização. 0 encerramento formal da ditadura civil-militar no Brasil inaugura movimento de liberalização política, tanto no âmbito doméstico quanto no internacional. Este ciclo de liberalização política é paralelo ao ciclo de liberalização econômica, influenciado pelo Consenso de Washington.

Ambos os ciclos de liberalização, forçados pelos constrangimentos internos e externos, passam a redefinir o modelo de inserção internacional adotado pelos 60 anos anteriores da história da política externa. A preferência pelo Estado desenvolvimentista, de base heterodoxa, pautado pela interferência direta na economia, foi substituído pelo estado "normal". Ambos os modelos de estado são similares aos paradigmas de análise elaborados para compreender a política externa desse período. Três são as construções conceituais sugeridas por Cervo (2002): a) o estado desenvolvimentista; b) o estado normal; c) o estado logístico. Os três paradigmas constituem a base argumentativa de Cervo para demonstrar as opções "iludidas" dos estrategistas envolvidos no processo decisório nos anos 1990. A “dança dos paradigmas" procura evidenciar a alternância entre três tipos de inserção em um curto período de tempo.

No entender de Cervo, o governo Cardoso viveu de três "ilusões" ao longo do seu mandato: em primeiro lugar, acreditou que a ordem multilateral global poderia produzir regras justas, transparentes e, portanto, democráticas as relações políticas e econômicas da sociedade internacional; em segundo lugar, a "ilusão das divisas", na qual se acreditou que a abertura da economia poderia resultar na atração de capitais externos não prejudiciais ao devido equilíbrio no balanço de pagamentos; em terceiro, depositou capital social no prestígio do presidente da República, como método para atender aos interesses nacionais.

As três "ilusões" representam as crenças dos atores-formuladores da política externa do período, notadamente o presidente Fernando Henrique Cardoso e os chanceleres Luiz Felipe Lampreia e Celso Lafer. A primeira “ilusão" citada é o objeto de análise relevante para interlocução com a hipótese adotada pela pesquisa. Cervo referese ao tipo de envolvimento do Brasil com os mecanismos multilaterais de participação como uma aposta baseada no idealismo/utopia de vertente grociana kantiana (CERVO, 2002, p. 14-16). A interpretação de Cervo situa o grocianismo adotado pelo Estado 
brasileiro como uma modalidade de idealismo, oposto ao entendimento adotado por Letícia Pinheiro.

Cervo, ao afirmar os anos 1990 como um período de ilusões baseados na utopia de funcionamento do sistema multilateral, procura evidenciar esta assertiva mediante o estudo do engajamento do Brasil em seis temas da agenda internacional: a) liberalismo econômico; b) meio ambiente; c) direitos humanos; d) segurança; e) multilateralismo comercial; f) fluxos de capitais.

Dos seis temas apontados por Cervo (2002), quatro - meio ambiente, direitos humanos, segurança e multilateralismo comercial - são diretamente relacionados à interação, com a dimensão multilateral de inserção. A questão ambiental e os direitos humanos são dois temas nos quais Cervo (2002) admite posicionamento pragmático do Brasil. Em contraposição, a segurança internacional e o multilateralismo comercial são objetos de crítica ao modelo de engajamento. Cabe descrever em detalhe os quatro itens de interesse, uma vez que fazem com que o autor designe a interação como utópica e idealista.

O item meio ambiente envolveu iniciativas anti-hegemônicas nas esferas bilateral, multilateral, regional e global. Destas, obteve retornos em três casos: conquistou o direito de sediar a Conferência sobre Meio Ambiente em 1992; a Cúpula da Terra inovou ao introduzir o desenvolvimento sustentável como um discurso de política externa, de modo a tornar indissociável o desenvolvimento da conservação ambiental; contribuiu para diminuir a dicotomia norte-sul por uma maior cooperação horizontal na questão.

Conforme demonstrado, o conceito de desenvolvimento sustentável, utilizado por iniciativa da diplomacia brasileira, foi combinado à estratégia diversificada de inserção internacional. Os resultados desta associação repeliram pressões desproporcionais para as economias em desenvolvimento, advindas das economias centrais, e criaram regime de proteção internacional para proteção da diversidade biológica e genética da Amazônia. A agenda ambiental da diplomacia brasileira, e agenda para os direitos humanos, constituem os únicos itens, citados por Cervo, como tributários de retornos para o estado brasileiro.

No que diz respeito aos Direitos Humanos, o envolvimento do Brasil com o tema foi dividido por Cervo em três etapas na história diplomática: a) o contexto de criação e 
momento após o lançamento da Declaração Universal dos Direitos Humanos da ONU, em 1948, complementado pela experiência adquirida com a Comissão Interamericana de Direitos Humanos e com a Comissão de Direitos Humanos da ONU; b) a postura isolacionista adotada pela Ditadura Militar durante a Guerra Fria; c) a atuação protagonizada pelo professor Antônio Augusto Cançado Trindade ao assumir o papel de presidente da Corte Interamericana de Direitos Humanos.

A última fase é concretizada, no plano interno, com adesão aos tratados gerais de proteção dos Direitos Humanos da ONU e da OEA, bem como às convenções internacionais especializadas. A percepção de juristas, diplomatas e legisladores no Brasil permitiu a elaboração de um conceito de Direitos Humanos interdependente do desenvolvimento e da democracia. A tese foi consolidada pela Conferência Mundial de Direitos Humanos sediada em Viena, no ano de 1993, a qual foi presidida pela delegação brasileira, encarregada de escrever a redação final do texto.

Tomando por base as questões ambiental e de Direitos Humanos, Cervo conclui que o Brasil assumiu uma postura kantiana, com resultados perceptíveis para o País e, também, para o aprofundamento dos regimes internacionais. Os dois temas seguintes apresentam esta mesma postura, ainda que sem resultados positivos para o Brasil.

Ao abordar a segurança nacional, Cervo critica o modelo de inspiração kantiana/grociana e afirma que o governo Cardoso teria sacrificado o papel estratégico das forças armadas. A força como ferramenta, voltada para aumentar o potencial de barganha, é desvalorizada em favor da persuasão e do enquadramento a regimes coletivos de segurança. A postura pacifista reverte a tendência de privilegiar a segurança nacional, iniciada nos anos 1970, para voltar-se à segurança coletiva. Os pressupostos ideacionais baseados no multilateralismo são aplicados, também, à agenda de segurança, tanto em termos de produção industrial-militar, como celebrando tratados em favor do desarmamento.

Diante de tais posturas, Amado Cervo afirma que o governo Cardoso renunciou à postura realista na arena internacional. 0 abandono à pretensão de adquirir um assento permanente no CSNU é citado por Cervo também como uma evidência da renúncia ao realismo. A "alta política” é, portanto, a dimensão na qual o Cervo tenta demonstrar a ilusão kantiana/grociana da política externa brasileira. 
O quarto item da agenda citada por Cervo, e último a ser apresentado, refere-se às relações econômicas internacionais. Cervo cita três equívocos dos economistas ligados ao governo Cardoso, os quais conduziram a mudança do modelo Desenvolvimentista para o Normal. 0 primeiro corresponde à crença de que protecionismo e crescimento econômico são dimensões excludentes. 0 segundo diz respeito à instrumentalização do comércio exterior para manter a inflação sob controle. 0 terceiro representa a convicção e a expectativa de que as potências avançadas fariam concessões à diplomacia brasileira no campo sensível das relações econômicas. As três apostas são entendidas por Cervo como "erros de cálculo" do governo Cardoso. Em especial, segundo o autor, o terceiro demonstra o funcionamento da matriz idealista kantiana/grociana nas negociações comerciais, e, por isso, será apresentado a seguir.

As rodadas de negociações do GATT, na qual o Brasil cede às pressões das economias centrais ao aderir aos Aspectos da Propriedade Intelectual Relacionados com o Comércio (TRIPS) em 1993, e ao aprovar a Lei de patentes em 1996. Cervo cita, também, os litígios de comércio, notadamente ligados a medidas antidumping. Ao serem levados aos mecanismos de solução de controvérsias da OMC, "padeciam de vício político [...]" (CERVO, 2002) e, desde a criação da OMC, em 1995, apenas 10\% dos julgamentos terminaram por favorecer os países periféricos.

Contudo, é com a Rodada do Milênio da OMC (ano 2000) que os limites do "sistema kantiano de comércio" são evidenciados. A Rodada, sediada na cidade de Seattle, foi acompanhada de protestos de manifestantes acampados e dos próprios países em desenvolvimento no processo de negociação. A não conclusão de um acordo sobre mecanismos democráticos reguladores do comércio internacional inviabilizou o aprofundamento do multilateralismo comercial global.

Ao analisarmos os quatro itens da agenda sugeridos por Cervo é possível identificar nos temas meio ambiente e direitos humanos uma argumentação propositiva à opção pelo multilateralismo da política externa brasileira. Em contraste, a dimensão da segurança e das relações econômicas demonstram compreensão depreciativa por parte do autor. Em especial, a segurança nacional é sacrificada em favor da segurança coletiva e as rodadas de negociações, bem como os contenciosos na OMC, são criticadas pelo autor por terem atingido resultados aquém do esperado. 
O balanço desta análise conduz Cervo a enquadrar a matriz ideacional da política externa em uma modalidade de idealismo. Os termos "ilusão kantiana”, "sistema kantiano de comércio", "inspiração idealista de vertente grociana e kantiana”, "visão kantiana da paz e da justiça global" são expressões empregadas por Cervo para descrever o período.

\section{Resultados}

Ao analisar os marcos teóricos na relação entre a política externa brasileira e o grocianismo, a seguinte indagação aparece como resultado: em que medida as teses de Fonseca Jr. (1998) e Vigevani, Oliveira e Cintra (2003), Lessa, Couto e Farias (2010), Pinheiro (2000), Cervo (2002) e Lafer (2009) dialogam entre si?

Após serem analisados os marcos teóricos da literatura na década de 1990, podese realizar as seguintes interfaces: em primeiro lugar, ao serem contrapostas as teses de Lafer e de Fonseca Jr., nota-se que ambos os autores, ao se referirem aos anos 1990, identificam e defendem uma maior participação do Brasil nos mecanismos de representação e inserção multilateral. A convergência, por um lado, reforça o traço grociano da política externa, uma vez que é identificado o compartilhamento de valores comuns entre os Estados, assim como uma busca por participar das instituições resultantes desta sociedade.

A noção de autonomia pela participação permite perceber uma equivalência entre os interesses nacionais e os valores da sociedade internacional na década de 1990 . É precisamente esta simetria à qual o grocianismo está se referindo, em especial Martin Wight ao questionar a dicotomia realismo/idealismo na análise das relações internacionais. Por outro lado, Fonseca Jr., ao afirmar um período de distância do Brasil na interação com o multilateralismo, evidencia uma maior ênfase dos interesses nacionais em detrimento aos valores da sociedade internacional. A modalidade de autonomia do País durante a Guerra Fria reforça alianças estratégicas bilaterais e, portanto, evidencia uma descrença do país em colher resultados baseados no fortalecimento da arquitetura jurídica internacional. Fonseca Jr. cita duas fases da política externa, de distância e de participação, e há maior aproximação do grocianismo com a fase de participação, que coincide com a década de 1990. Adicionalmente, ao considerarmos o "grocianismo como uma constante", os apontamentos de Lessa, Couto e Farias (2010), são particularmente apropriados. Os dados extraídos das comunicações entre Brasília e Genebra demonstram 
um desejo de maior participação do Itamaraty nos fóruns e nas reuniões de coordenação e, por óbvio, de decisão dos organismos multilaterais.

Desta observação, duas ponderações são possíveis: a) pode-se identificar, uma vez que tanto Lafer, quanto Fonseca Jr. são atores políticos dos anos 1990, um limite pouco definido entre a obra dos autores como acadêmicos e propagandistas da política externa do período. Caso este argumento fosse aceito, a validade acadêmica dos argumentos estaria colocada em cheque. De outra perspectiva, como a tese de Lafer e de Fonseca Jr., são encontradas em outros atores da literatura, em Martin Wight/Hedley Bull e Pinheiro/Cervo, respectivamente, a legitimidade metodológica permanece razoável; b) a convergência de ambas as perspectivas para os anos 1990 reforça a hipótese do grocianismo na atuação multilateral do Brasil, uma vez que ocorre uma coincidência entre o aprofundamento das regras do sistema e os interesses do Brasil em relação ao aprofundamento destes arranjos, resultado de um incremento na sua participação.

Adicionalmente, ao considerarmos o "grocianismo como uma constante", os apontamentos de Lessa, Couto e Farias (2010), são particularmente apropriados. As conclusões extraídas do universo pesquisado pelos autores exigem, na observação da política externa durante a Guerra Fria, uma repartição analítica entre intenção e ação política. Enquanto a exposição de Fonseca Jr. (1998) identifica um período de distanciamento, Lessa, Couto e Farias (2010) introduzem uma alcunha ao conceito, na medida em que afirmam o distanciamento ser resultado das ações e não a intenção dos estrategistas do período.

A impossibilidade de generalização do conceito de "autonomia pela distância" aproxima e reforça o modelo ideacional sugerido por Lafer. Desta forma, o termo "constantes grocianas de atuação multilateral" estaria presente ao longo de toda história diplomática desde suas origens históricas encontradas pela atuação de Ruy Barbosa na Haia. De fato, a análise de Lafer aponta a criação de uma conduta típica ideal da política externa, influenciada pela força da identidade internacional do Brasil.

Entre uma conduta típica ideal e a concretização dessa conduta, existe uma interação intraburocrática de necessária consideração para a avaliação da política externa. Os mecanismos de decisão, ligados aos interesses em conflito dos múltiplos agentes na definição das políticas públicas, exigem a abertura da "caixa-preta" do Estado para uma análise que leve em consideração as intenções e as ações empregadas. A Conjuntura Global, vol. 5 n. 1, jan./abr., 2016, p. 94-114. 
literatura, no entanto, privilegia a observação apenas das ações, ou seja, dos fatos. Como resultado, a não identificação das características do processo decisório resulta em conclusões adotadas pelo conjunto da literatura passíveis de revisão.

As considerações de Pinheiro sobre o multilateralismo na política externa, contudo, advertem para o "desejo de autonomia" como um traço de permanência, que aproximaria o Brasil do paradigma realista da teoria de relações internacionais. Pinheiro estabelece uma divisão histórica da política externa definida por uma adaptação a este objetivo, ora por meio da fórmula americanista, ora pela globalista. Diante desta afirmação, a hipótese baseada em Lafer, na qual o grocianismo seria uma constante, entraria em choque com o realismo como uma constante, como afirmado por Pinheiro.

Desta forma, as duas interpretações da atuação multilateral do Brasil, uma sendo a de Lafer (2009) e Lessa, Couto e Farias (2010) e a outra de Pinheiro (2000) revelam uma tensão entre duas constantes: "o desejo de participação" e o "desejo de autonomia". A hipótese, na qual está baseada a interpretação de Pinheiro, aproximaria a diplomacia brasileira do realismo devido ao "desejo de autonomia" ser encontrado sob distintas modalidades, mas estar sempre presente. Por outro lado, devido ao engajamento no multilateralismo ser uma característica de maior volatilidade, como é corroborado por Fonseca Jr. ao demonstrar a Guerra Fria, como um período de distância e o Pós-guerra como de participação, a busca por autonomia representaria um traço de maior estabilidade na política externa. Os dados apresentados por Lessa, contudo, auxiliam a demonstrar o "desejo de participação" como uma constante na história da diplomacia brasileira, ou seja, é possível identificar uma tensão ${ }^{9}$ entre participação e autonomia como duas constantes em conflito, ao menos no nível ideacional de análise $\mathrm{e}^{10}$.

\footnotetext{
${ }^{9}$ De fato, é precisamente esta tensão à qual Martin Wight e Hedley Bull estão se referindo ao inaugurar a tradição grociana/racionalista de análise. Wight identificava em seu pensamento um pêndulo entre realismo e revolucionismo, de modo que não se sentia satisfeito com uma posição teórica limitada por estes dois extremos. A mecânica do racionalismo criada por Wight estabelece uma forma de análise que transita de um ponto a outro, mesmo que apresente uma posição intermediária. Assim, a noção de pluralismo ontológico encontra paralelo com a tensão entre "desejo de participação" e "desejo de autonomia" na política externa.

${ }^{10}$ Estrutura argumentativa similar é apontada por Fonseca (1998) ao comentar as teses da escola inglesa. A ruptura com os extremos do realismo e do revolucionismo, como modelos ideais de ordem na sociedade internacional, esconde um "continuum complexo" em que ocorre uma sucessão de fases orientadas pelo realismo e outras orientadas pelo revolucionismo. A história revela a coexistência dos modelos de ordem, até mesmo, em períodos de aparente estabilidade ou conflito. Fonseca cita a Guerra Fria como exemplo desta ontologia paradoxal.
} 
Fonseca e Pinheiro revelam formas similares de análise da sociedade internacional e da política externa brasileira, respectivamente. Apesar de chegarem a conclusões distintas, demonstram existir uma tensão entre pressupostos hobbesianos, kantianos e grocianos nas relações internacionais. Este aparente paradoxo é compreendido por Pinheiro mediante raciocínio baseado na noção de "complementariedade" de antigas e novas ideias incorporadas à política externa (PINHEIRO, 2000, p. 322). Tal noção expõe uma tensão entre a visão hobbesiana e a visão grociana na década de 1990. Curiosamente, a última interpretação fornecida pela literatura, baseada em Cervo, aponta para os anos 1990, como uma fase idealista da política externa. Enquanto Pinheiro inclui o período na perspectiva realista e Lafer na perspectiva grociana, Cervo defende o estabelecimento de uma "ilusão kantiana" na elite dirigente do MRE, tal como demonstrado pela exposição.

Em síntese, a literatura revela três possibilidades de interpretação da atuação multilateral do Brasil: a) a realista, derivada da análise de Pinheiro (2000); b) a grociana, derivado de Lafer (2001) e complementado por Fonseca (1998) e Lessa, Couto e Farias (2010); c) a idealista, derivado de Cervo (2009).

\section{REFERÊNCIAS}

BULL, Hedley. A sociedade anárquica: um estudo da ordem na política mundial. São Paulo: UnB, 2002.

CERVO, Amado Luiz. Conceitos em relações internacionais. Revista Brasileira de Política Internacional, v. $51, \quad$ n. 2 , p. 8-25, 2008. Disponível em: <http://www.scielo.br/pdf/rbpi/v51n2/v51n2a02.pdf>. Acesso em: 29/10/2012. $2008 b$.

. Inserção internacional: formação dos conceitos brasileiros. São Paulo: Saraiva, 2010.

. História da política exterior do Brasil. 3. ed. Brasília: Universidade de Brasília, FONSECA JR. G. A legitimidade e outras questões internacionais: poder e ética entre as nações. São Paulo: Paz e Terra, 1998

HURRELL, Andrew. The Quest for Autonomy: the evolution of Brazils role in the International System, 1964-1985. Oxford University, DPhil Thesis, 1986. 
LAFER, Celso. A identidade internacional do Brasil e a política externa brasileira: passado, presente e futuro. ed. 2. São Paulo: Perspectiva, 2009.

LESSA, Antônio Carlos; COUTO, Leandro Freitas; FARIAS, Rogério de Souza. Distanciamento versus engajamento: alguns aportes conceituais para a análise da inserção do multilateralismo brasileiro (1945-1990). Contexto Internacional, Rio de Janeiro , v. 32, n. 2, dec. 2010. Disponível em: <>. Acesso em: 10/4/2016.

MOURA, Gerson. Autonomia na Dependência: A Política Externa Brasileira de 1935 a 1942. Rio de Janeiro: Nova Fronteira, 1982.

PINHEIRO, Letícia. Traídos pelo desejo: um ensaio sobre a teoria e a prática da política externa brasileira contemporânea. Contexto Internacional. Rio de Janeiro, v. 22, n. 2, jul./dez., p.305-335, 2000.

SOUZA, M. E. RESENDE, MAXIMO, J. R. A difusão da escola inglesa na américa latina: a EI e o discurso diplomático brasileiro. Conjuntura internacional. Belo Horizonte, Capa, v. 12, n.1 (2015) Disponível em: http://periodicos.pucminas.br/index.php/conjuntura/article/view/9073. Acesso em: 27/04/2016.

TICKNER, Arlene B. Los studios internacionales en América Latina: ¿Subordinacón intelectual o pensamiento emancipatorio? Bogotá: Universidad de los Andes, CESO, Departamento de Ciencia Política: Alfaomega Colombiana, 2002.__. Seeing IR Differently: Notes from the Third World. Millennium, v. 32, N. 2, 2003, p. 295-324.

VIGEVANI, Tullo; OLIVEIRA, Marcelo F. de; CINTRA, Rodrigo. Política externa no período FHC: a busca de autonomia pela integração. Tempo Social. São Paulo, v. 15, n. 2, nov., 2003. Disponível em: <http://ref.scielo.org/q59q2h>. Acesso em: 10/4/2016.

VIGEVANI, Tullo e CEPALUNI, Gabriel. Brazilian Foreign Policy in Changing Times: The Quest for Autonomy from Sarney to Lula. Maryland: Lexington, 2009.

WIGHT, Martin. A política do poder. Brasília: UnB, 1985.

Western values in international relations. In: BUTTERFIELD, Herbert; WIGHT, Martin. (Orgs.). Diplomatic investigations: essays in the theory of international politics. London: Allen and Unwin, 1966.

. International theory: the three traditions. WIGHT, Gabriele; PORTER, Brian (Eds.). London: Leicester University, 1991. 